This item was submitted to Loughborough's Research Repository by the author.

Items in Figshare are protected by copyright, with all rights reserved, unless otherwise indicated.

\title{
Graphicality: why is there not such a word?
}

PLEASE CITE THE PUBLISHED VERSION

http://www.drs2016.org/proceedings

\section{PUBLISHER}

Design Research Society

\section{VERSION}

VoR (Version of Record)

\section{PUBLISHER STATEMENT}

This work is made available according to the conditions of the Creative Commons Attribution-NonCommercial 4.0 International (CC BY-NC 4.0) licence. Full details of this licence are available at: http://creativecommons.org/licenses/by-nc/4.0/

\section{LICENCE}

CC BY-NC 4.0

\section{REPOSITORY RECORD}

Harland, Robert G., and David Craib. 2019. "Graphicality: Why Is There Not Such a Word?”. figshare. https://hdl.handle.net/2134/21863. 


\title{
Graphicality: why is there not such a word?
}

\author{
Robert Harland ${ }^{a}$, David Craib ${ }^{b}$, Robert Harland ${ }^{*}$ \\ aLoughborough University, UK

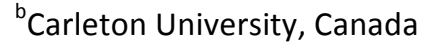 \\ *Corresponding author e-mail: r.g.harland@lboro.ac.uk
}

\begin{abstract}
The concept of graphicality first appeared in the work of Edgar Allan Poe. Taking its title from Poe's painterly metaphor, this paper seeks to understand how graphicality may inform aspects of design thinking that have been neglected. We explore the current use, origins and aspects of graphicality, and contextualise it in some real world scenarios to reaffirm how we live in a graphic age, and how graphicality must be better understood in the way we comprehend other displays of human ability, such as musicality. Poe provides us with a starting point for relating the physical and mental domains of image interpretation. Graphicality is shown to work on a continuum between subjectivity and objectivity, not as something to be measured but appreciated in how it enhances understanding and knowledge. This has implications for many academic disciplines, specifically in how it enhances our appreciation of the graphic in graphic design.
\end{abstract}

Keywords: graphicality, literary theory, cognitive science, textual studies

\section{Introduction}

Approached from the perspective of graphic design, the impetus for this paper has been to establish what constitutes graphicality. The inquiry began with the rudimentary question: Is there such a word? If so, what does it mean and how is it used? Early speculations were that the concept is most probably related to something that can be measured, but with some astonishment a search for its origins suggested something very different.

Thirty years ago the word graphic did not appear in dictionaries except as a listing under the generic word "graph". Yet, graph is now inflected by various forming adjectives and nouns that determine the state or quality of being graphic or graphical, performing graphically, defining graphicness, and displaying graphicacy. To this can now be added the word graphicality to denote the condition of being graphical. Other words with the same suffix include musicality, theatricality, monumentality, literality or humility. We generally

This work is licensed under a Creative Commons Attribution-NonCommercial 4.0 International License. 
understand what these words mean in that, for instance, musicality refers to the ability or quality associated with music. In this paper we ask what does graphicality stand for? What are the abilities or qualities associated with being graphic?

We reflect on the state of graphicness by examining the properties and factors associated with graphicality. The aim is to explore how the concept of graphicality is useful in design by exposing the various meanings that have been assigned to graphicality. We will achieve this by outlining some examples of how we live in an increasingly sophisticated graphic age, by introducing the emergence of the term graphicality, discussing its current usage, and speculate on the potential it offers design discourse.

\section{Living in a graphic age}

The eponymous tendency to define an era by age - be it industrial, digital, urban or anything else that delineates time and space - is a predisposition of our time. Some phenomena are so much a part of our everyday existence they defy time and space by adapting to cultural, societal, economical and technological change. Two examples are the act of reading and writing, or the notion of human settlement.

In 2008 we crossed a threshold when more than half of the world's population came to live in urban environments. This deemed that we now live in the urban age (McGrath, 2013, p.8). Similar to the way the majority of people who live in urban settlements have led us to refer to an urban age, the majority of people who now read and write (UIS Fact Sheet, 2013) suggests we also live in a literary age. With the increasing acknowledged importance that so called visual language plays in our lives it has also been suggested we have embarked on a "visual information age" (MacEachren, 1995, p.v). More succinct than this is the view that we live as much in a "graphic age" (Harland, 2012) in acknowledgement that graphic communication is so fundamental to our everyday existence. This reflects in not only our ability to communicate through various forms of graphic representations that combine cognitive and corporeal experience, but also a proliferation of all things graphic to define interfaces, equalizers, novels, tablets, comics, even violence. If further substantiation is needed, in television programmes about science, sport and culture, graphic phenomena increasingly define a state of things. For example, the physicist Brian Cox shows us the power of tides "graphically"; the photographer William Klein's early geometric work is said to be influenced by "a strong graphic eye"; or the "very graphic" nature of art house movie Who are you, Polly Magoo.

This corresponds with the increasing complexity of graphic display in everyday objects, and the visual culture associated with leisure activities such as music and sport. For example, the death of David Bowie reminds us of just how important the vision in "sound and vision" has become, typified on the cover of his album Aladdin Sane in 1973. Compared to the relatively sedate appearance of The Beatles' album covers some ten years earlier with their suits and ties, portraying a degree of formality, the lightening flash across the Bowie's face and his dyed orange hair emphasised dramatic change in what had become acceptable standards in 
popular culture after the upsurge of Pop Art. With regards to sport, in 1966 England won the football world cup wearing plain red shirts with nothing more than the "three lions emblem" on their chest and white numbers on their back, kicking a plain tan-coloured football. In the 2014 world cup in Brazil, English players wore shirts (white or red) featuring the three lions positioned underneath a single gold star signifying the number of times they had won the tournament, the emblem also appearing on shorts. This was accompanied with a custom-designed typeface for numbers (also containing the three lions emblem) and names emblazoned on player's back. Additionally, the Nike kit sponsor symbol featured on shirts, shorts and socks.

Furthermore, the 2014 World Cup tournament ball carried the Adidas mark, FIFA World Cup symbol, and official match ball name with a new overall abstract surface pattern, which has become the norm for each tournament. Players could be seen kicking the ball wearing Adidas Predator Instinct patterned boots with geometric black and white pattern and orange/red stripes synonymous with the Adidas visual identity. This is part of a gradual graphic transition since 1998 from the simple three white stripes on black boot consistent with the basic boot appearance since 1958. See figure 1.
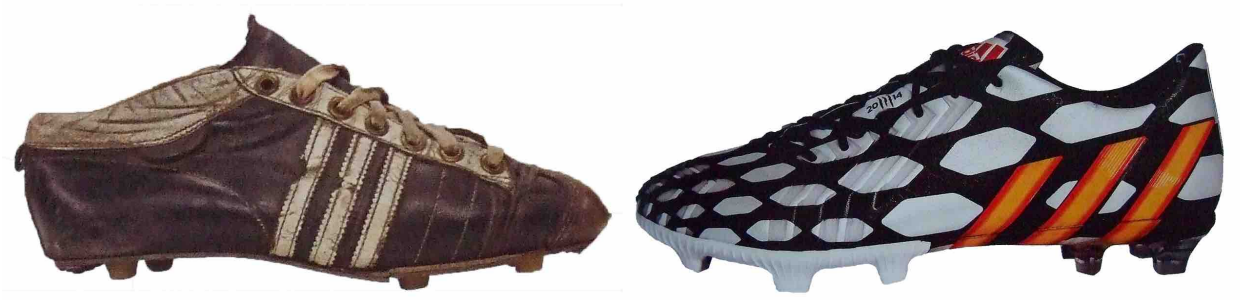

Figure 1 Adidas football boots from 1958 (left) and 2014 (right), illustrating the change in surface patterning. The three stripe device associated with the brand visual identity is still present and both are distinctive, but the latter displays more complex imagery and integration with the product in the way the sole is also a surface for pattern. Source: Creative Review (June 2014, pp.32-33)

These graphic objects find their way into local parks and playing fields as young aspiring footballers wear replica boots and kits, and kick imitation branded footballs. Their goal is as much to display their graphic prowess through the graphic complexity associated with the sporting world, as part of emulating their football heroes.

\section{The origin and use of graphicality}

Graphicality as a term first emerged in the humanities, but has since been further used within the disciplines of computational mathematics, cognitive science, and textuality studies. In this section we describe the origin of the word and trace its usage across a variety of academic disciplines. 


\subsection{The origin of graphicality}

The term graphicality appears to have been first introduced by author, poet, editor and literary critic, Edgar Allan Poe in the mid-1840's through the discipline of literary criticism. Specifically referring to Margaret Fuller's Summer on the Lakes, he commented:

"Many of the descriptions in this volume are unrivalled for graphicality, (why is there not such a word?) for the force with which they convey the true by the novel or unexpected, by the introduction of touches which other artists would be sure to omit as irrelevant to the subject. This faculty, too, springs from her subjectiveness, which leads her to paint a scene less by its features than by its effects." (Poe, 1858, p.74)

In further illustrating graphicality, Poe quoted Fuller's description of Niagara, italicizing the passages that inspired this newly awakened term:

"Daily these proportions widened and towered more and more upon my sight, and I got, at last, a proper foreground for these sublime distances. Before coming away, I think I really saw the full wonder of the scene. After a while it so drew me into itself as to inspire an undefined dread, such as I never knew before, such as may be felt when death is about to usher us into a new existence. The perpetual trampling of the water seized my senses. I felt that no other sound, however near, could be heard, and would start and look behind me for a foe. I realized the identity of that mood of nature in which these waters were poured down with such absorbing force, with that in which the Indian was shaped on the same soil. For continually upon my mind came, unsought and unwelcome, images, such as had never haunted it before, of naked savages stealing behind me with uplifted tomahawks. Again and again this illusion recurred, and even after I had thought it over, and tried to shake it off, I could not help starting and looking behind me." (Fuller, 1843. p.5)

Poe's literary definition of graphicality referred to a scene described indirectly through the introduction of non-central items, such as subjective feelings. The main object of the narrative is described through the non-direct signs surrounding and contributing to it; the narrator fleshes-out the key ideas, objects and expressions through personal insight. Poe believed in the effectiveness of this scheme, employing literary graphicality in his own work, perhaps the key reason why his works were so widely illustrated by such artists as Manet, Gauguin, Beardsley, Whistler and many hundreds of others (Pollin, 1989, p.3). One of Redon's lithographs is shown in Figure 2.

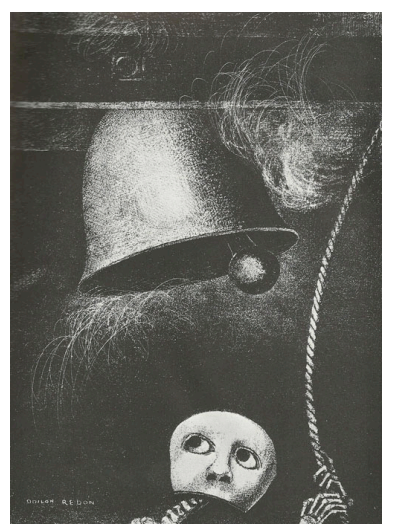

Figure 2 Odilon Redon's third lithograph from series À Edgar Poe. (Pollin, 1989, p.27) 
Literary graphicality allowed Poe and others to offer the reader what was required to paint a mental image of a situation in a way contrary to direct and exhaustive description (he disapproved of the use of the unnecessary) yet in the personal and subjective. As Poe stated, "An outline frequently stirs the spirit more pleasantly than the most elaborate picture" (1880, p.627).

\subsection{The use of graphicality}

Although first introduced as a literary concept, it has become more useful in computational mathematics, cognitive science and textuality studies. In mathematical graph theory, a graph is "realized" (exists) when it obeys the Erdős-Gallai theorem, also known as the graphicality equation. "Sequences that admit realizations as simple graphs are called graphical, and we refer to their realizability property as graphicality" (Del Genio, Gross, \& Bassler, 2011, p.1). Simple graphs are composed of nodes (points) and links (lines connecting the nodes). When a simple graph can be constructed by a set of nodes and links "without any parts left over" as shown in Figure 3, it exhibits graphicality (K. E. Bassler, personal communication, October $6,2015)$.

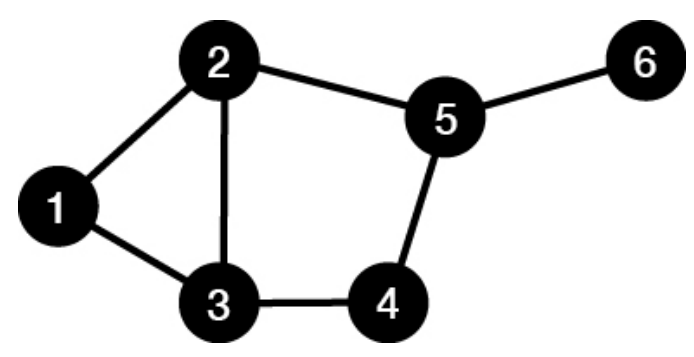

Figure 3 A set of mathematical nodes and links forming a simple graph exhibiting graphicality.

The logician and cognitive scientist, Atsushi Shomojima explores the relationship and boundaries between graphicality and linguisticity (the quality of being linguistic) by applying concepts from philosophy, logic, artificial intelligence and cognitive psychology. His aim is not to prove that there is a distinct boundary between the two, but to find if there are properties shared by all graphic representations and no linguistic representations, or viceversa (Shimojima, 1999, p.314). Shimojima's findings are inconclusive, as none of his seven proposed methods satisfy his requirements, meaning that it remains possible that linguisticity and graphicality are not mutually exclusive states, sharing various properties.

Dual-coding theory, discussed later in this paper, suggests that the human brain shares graphical and linguistic stimuli through referential connections, suggesting that no such boundary exists (Paivio, 1986, pp.53-83), but more research should be done, through disciplines such as philosophy and logic, cybernetics, and systems-thinking, to define the behaviour of such boundaries - helping to further resolve this issue.

Textuality studies offer a unique perspective from which we can witness several overlapping properties of linguisticity and graphicality. Morris Eaves describes the "interwoven central 
concerns" of textuality as authority, transmission and representation (Eaves, 2002, p.99). Eaves sees graphicality as having the same central concerns as textuality and implies that they are therefor inseparable concepts, (Eaves cites the negative effects of the disembodiment of William Blake's illustrated texts, one of which is shown in Figure 4, as they were re-published without their original illuminations).

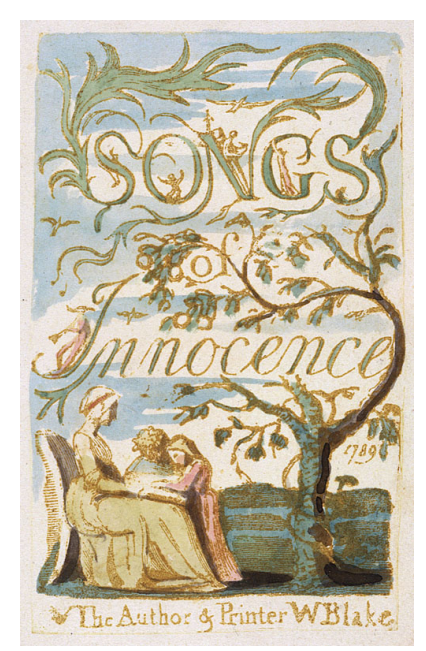

Figure 4 The cover of William Blake's "Songs of Innocence". (Retrieved from http://tinyurl.com/ox3285f)

Poetry often solicits the use of graphical properties to convey meaning. Drucker (2015) corroborates the universally graphical nature of textual poetry, yet notes that only some examples exploit graphicality sufficiently, becoming diagrammatical, employing further spatial modulations. Graphical expressions such as line breaks, distance between words, positioning for visual emphasis, referential iconography, musical score-like and script-like mechanisms, and employing mise-en-scene, are just some of the visual mechanics of this kind of poetry. One example is Frédéric Forte's Minute-Operas, which is said to employ "dynamic expressions" of graphicality while reflecting values of earlier works of the Italian Futurists such as Filippo Tommaso Marinetti (Drucker, 2015). See Figures 5 and 6.

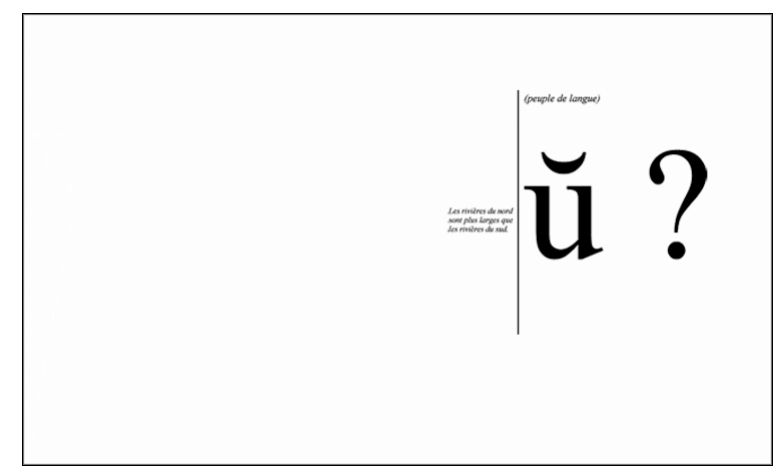

Figure 5 Poem from Forte's "Minute-Operas". (Retrieved from http://tinyurl.com/nw54xcd) 


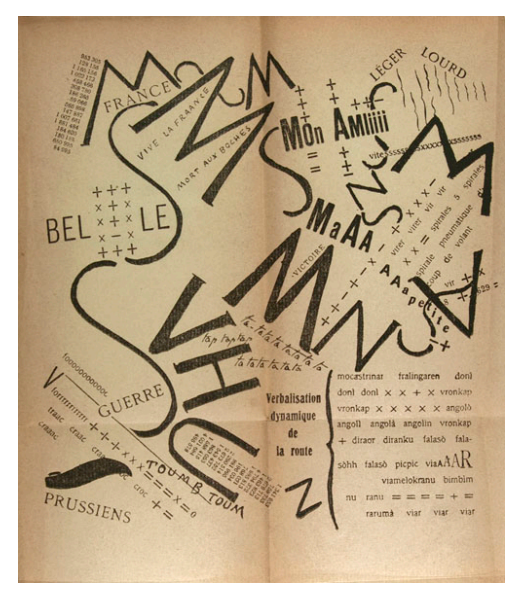

Figure 6 Section of Marinetti's "Les Mots en Liberté". (Retrieved from http://tinyurl.com/pssesvv)

In these various fields graphicality is at times associated with simplicity and efficiency, as in the case of computational mathematics. The use of graph theory in other disciplines such as geography means graphicality is also present in other domains. In cognitive science this extends to mean other forms of representation such as a geometric diagram, map of a country or a print of Mount Fuji by Hokusai. "Pictures, images and diagrams are graphical representations while sets of sentences are linguistic representations" (Shimojima, 1999, p.313). This flawed duality (flawed in the sense that linguistic representations are also graphic representations) sets apart "drawing" from "writing" practice in such a way that graphical representation is more diverse than the representation of words through writing systems limited to alphabetic characters. In this scenario, where the boundary between graphicality and linguisticity has been elusive, it is because as soon as linguistics moves away from spoken sound it assumes the more material qualities readily associated with graphicality.

Current use of the term thus refers to concrete manifestations more visual than verbal, picture than language, image than word, depictive than written, figural than discursive, shown than said - all standing in opposition to reinforce what Elkins (1999: 84) asserts "the domain of images" as a poorly understood field of inquiry. And yet the origin of graphicality is seemingly linguistic.

Poe's use of graphicality to stand for the power of word compositions to invoke truth, novelty, and the unexpected, also utilizes a supporting painterly metaphor to impress on the reader a feeling of subjective sensation. The sole use of words to do this - compared with the mathematician's medium of the graph with its reliance on line, shape, spatial relations, words and numbers - contrasts with the opposing graphic-linguistic duality. But it is an acknowledgement of the picturing intended in textuality studies and its assimilation of verbal-visual form.

A critical question therefore arises from these variable descriptions of graphicality. How do mathematical, linguistic, textual and visual approaches incite graphicality? One answer is found in Allan Paivio's (1986, pp.53-83) concept of cognition known as dual-coding theory. 
In dual-coding theory, the brain is believed to process signals through two separate channels of perception: one visual, and one verbal. The visual stream processes images and events, naturally fostering non-verbal modes of representation, but the other stream processes language and text. So how might this stream stimulate our perception of graphicality? During the process of dual-coding, some words entering the verbal processing channel are capable of referencing imagery, and through the referential connections between the verbal and non-verbal processing channels, words and text cause us to visualize images in our minds (see Figure 7). Because of the brain's ability to establish referential connections between the two processing channels, words can become images and images can become words. Just as easily as we can comment on something we see, we can visualize a thing communicated to us through speech or text (Paivio, 1986, pp.53-83).

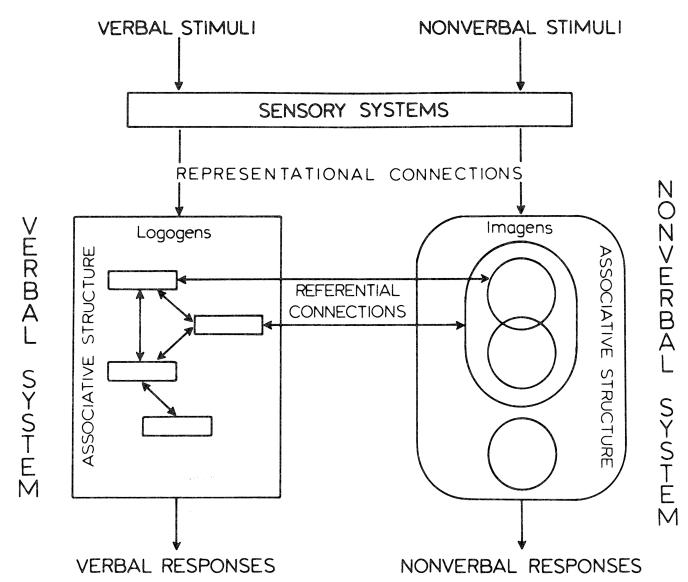

Figure 7 Diagram of dual coding process. (Paivio, 1986, p.67)

Contemplating graphicality from this perspective acknowledges it as a transmissive state between form and the neurological process of observation and interpretation. It provides one explanation for the continuing argument about the way humans think through verbal and non-verbal systems, said to be one of the most "vexing issues" (Manghani, Arthur, \& Simons, 2006, p.195) in cognitive science. Common parlance for the visual dualism is the "mind's eye" or "mental imagery". But when there is the same emphasis as Poe - on words that paint pictures - these have also been called "vivid verbal representations", "verbal imagery and metaphoric language" or "imagistic language". Further distinction has been made as "graphic images [pictures, statues, designs]" and "mental images [dreams, memories, ideas, fantasmata]" as determined by different intellectual disciplines (Mitchell, 1986, p.10) whereas others directly associated with graphic objects refer simply to the "graphic eye" (Poyner, 2002) in association with graphic design. Graphicality in this real sense purports to both the corporeal and incorporeal.

\section{Aspects of graphicality}

"Properties like size, scale, position etc. all have values in spatial systems as well as graphical ones, but they are essential to graphical expression. So, I consider 
graphicality to be those properties and characteristics that are inherent to visual expression." (Drucker, personal communication, September 27, 2015)

Graphicality is a fundamental mode of expressiveness, and can be contrasted to other modes of expression, such as musicality, theatricality, and vocality (Drucker, personal communication, September 27, 2015). Various theorists have deconstructed the elements of graphicality. Based on Gestalt perception principles, Rudolph Arnheim (1974) describes the visual aspects of balance, shape, form, space, light, colour, movement, and dynamics and expression. Jacques Bertin ([1967] 1983, p.42) refers to size, value, texture, color, orientation and shape, within a signifying space (space) and while admitting movement's role, discounts it, focusing on static graphics. Colin Ware (2013, pp.153-156) introduces "preattentive cues", which fall under the categories of form, colour, motion, and spatial position, and include various attributes such as size, orientation, hue, intensity and twodimensional position and others.

However, these various word groupings are a random set of conditions and characteristics that do not distinguish between defining properties and external factors. For example, colour or shape are defining properties of an object whereas 'balance' and 'spatial position' are external factors. This randomness needs closer attention.

From the perspective of art practice, a more succinct set of principal elements that contribute to our understanding of objects in the visual world have been identified as line, shape, tone, colour, texture, form, scale, space and light (Cohen \& Anderson, 2006, p.9). But again it is not a consistent group of descriptors. These nine elements can be divided into two parts; the first six being defining properties but the last three - scale, space and lightare external factors that regulate or govern the visual appearance in a similar way to balance, orientation, and movement.

These properties and factors are organised in various combinations as configurational patterns to establish coherent representations. As design, these properties have been explained as multimodal, that is, a combination of elements working together and in parallel. For example, Edward Tufte focuses chiefly on principles of design, including:

1. Using words, numbers and illustrations together: this approach to meaning creation is known as multimodality.

2. Visual parallelism: using different sign systems or modes of communication to mutually reinforce the meaning of a visual message (Tufte, 1997, p.151).

Some of the ways that defining properties, or visual elements have been organised have been explained through perception. For example, Jacques Bertin describes four systems that organize visual elements, shown in Figure 8, involving associative, selective, ordered and quantitative perception (Bertin, [1967] 1983, p.44).

1. Associative perception: enables us to see an overall structure, without variance.

2. Selective perception: enables us to see a single category clearly, and can isolate it 
3. Ordered perception: enables us to compare at least two different data sets in a graphic to each other

4. Quantitative perception: enables us to define a quantitative ratio between data.

(Bertin, [1967] 1983, pp.65-67)

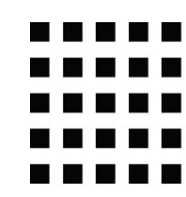

1

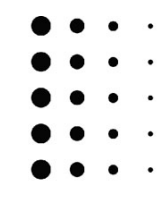

2

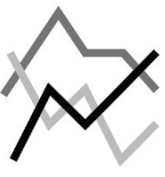

3

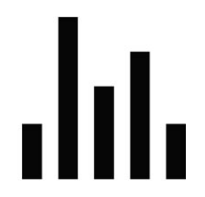

4

Figure 8 Bertin's levels of perception: association (1), selection (2), ordered (3) and quantitative (4).

(Craib 2015)

Bertin's concepts help to explain how graphicality is distinguished in organizational terms, yet Charles Sanders Peirce sees three more relational modes, which can be applied to visual systems. These include symbolic mode, a fully arbitrary mode where the relation to its subject must be agreed upon, iconic mode which visually imitates its subject, and indexical mode which refers to its subject through a conceptual link (Chandler, 2007, pp.36-37). Arnheim's category of expression describes what graphicality achieves when the various aspects add up to more than the sum of their parts (Arnheim, 1974, p.444). From this, Drucker's description - the properties and characteristics of graphicality - can be synthesized into what they achieve through visual expression, or visual semiosis. These various descriptions of the elements and behavioral characteristics of graphic systems are listed in Table 1. 
Table 1 Aspects of graphicality

\begin{tabular}{|c|c|c|c|c|c|c|c|}
\hline & $\begin{array}{l}\text { Arnheim } \\
1954\end{array}$ & $\begin{array}{l}\text { Bertin } \\
1967\end{array}$ & $\begin{array}{l}\text { Ware } \\
2013\end{array}$ & $\begin{array}{l}\text { Cohen \& } \\
\text { Anderson } \\
2006 \\
\end{array}$ & $\begin{array}{l}\text { Tufte } \\
1983-1990\end{array}$ & $\begin{array}{l}\text { Pierce } \\
1867\end{array}$ & $\begin{array}{l}\text { Accumulated } \\
\text { aspects of } \\
\text { graphicality }\end{array}$ \\
\hline \multirow[t]{6}{*}{$\begin{array}{l}\text { Defining } \\
\text { properties }\end{array}$} & shape & shape & $\begin{array}{l}\text { shape } \\
\text { line length } \\
\text { line width } \\
\text { curvature } \\
\text { convex } \\
\text { concave }\end{array}$ & $\begin{array}{l}\text { line } \\
\text { shape }\end{array}$ & & & shape \\
\hline & & size & & scale & $\begin{array}{l}\text { smallest } \\
\text { effective } \\
\text { difference }\end{array}$ & & size \\
\hline & form & & & form & & & form \\
\hline & & value & $\begin{array}{l}\text { value } \\
\text { intensity } \\
\text { blur }\end{array}$ & tone & & & tone \\
\hline & & texture & & texture & & & texture \\
\hline & colour & colour & colour & colour & colour & & colour \\
\hline \multirow[t]{11}{*}{$\begin{array}{l}\text { External Factors } \\
\text { Relational }\end{array}$} & space & $\begin{array}{l}\text { signifying } \\
\text { space }\end{array}$ & position & space & flatland & & space \\
\hline & light & & & light & & & light \\
\hline & & orientation & line orientation & & & & orientation \\
\hline & balance & & & & & & balance \\
\hline & movement & & $\begin{array}{l}\text { flicker } \\
\text { direction }\end{array}$ & & & & movement \\
\hline & dynamics & & & & small multiples & & dynamics \\
\hline & & & & & $\begin{array}{l}\text { layering \& } \\
\text { separation }\end{array}$ & & $\begin{array}{l}\text { layering \& } \\
\text { separation }\end{array}$ \\
\hline & & & & & parallelism & & multimodality \\
\hline & & & & & & $\begin{array}{l}\text { symbolic } \\
\text { relations }\end{array}$ & $\begin{array}{l}\text { symbolic } \\
\text { relations }\end{array}$ \\
\hline & & & & & & $\begin{array}{l}\text { iconic } \\
\text { relations }\end{array}$ & iconic relations \\
\hline & & & & & & $\begin{array}{l}\text { indexical } \\
\text { relations }\end{array}$ & indexical relations \\
\hline \multirow[t]{4}{*}{$\begin{array}{l}\text { External Factors } \\
\text { Organisational }\end{array}$} & & association & $\begin{array}{l}\text { spatial } \\
\text { grouping }\end{array}$ & & & & association \\
\hline & & selection & & & & & selection \\
\hline & & order & & & & & order \\
\hline & & quantity & numerosity & & & & quantity \\
\hline
\end{tabular}

These various aspects of graphicality extend what Kepes (1944, pp.15-16) referred to as physiological and psychological responses to "plastic" experience, that is, the "formative quality, the shaping of sensory impressions into unified, organic wholes". Kepes recognised that an external and internal frame distinction served nothing more than a convenience because the real importance lay in the transformation that happens between the two. This is what this paper refers to as graphicality. For our convenience, we have grouped aspects into defining properties, external factors and organizational principles, but Kepes preferred to group many of these as "spatial forces", including "Positions, directions, and differences in size, shape, brightness, colour and texture" (1944, p.20). This spatial interpretation has since been extended in a discussion about visual perception and "visual attributes", divided as "spatial" and "area-fill" (von Engelhardt, 2002), building on the work of Bertin ([1967] 1983) and Kepes. More detailed analysis of this is required but this will not be undertaken 
here. Instead, we turn to a different interpretation of the word form, and its relationship to context.

\section{The relationship between graphic form and context}

Having reviewed the various ways graphic elements have been discussed, and alluded to a sense of purpose in communication, meaning creation, or visual expression, we now move beyond defining properties, external factors and organizational principles to consider the relationship of graphic objects to their wider context. This will help to determine the relational aspects of graphicality's intrinsic (defining) and extrinsic (determining) qualities.

Earlier the word "form" inferred a three-dimensional object but it may also be interpreted to mean a manifestation of any kind, not just relational factors. This allows us to benefit from Christopher Alexander's discussion about the relationship between form and context (1964) and elaborate on the external factors to further determine that graphicality is a context dependent state. Alexander's view is that "context defines the problem" and the "form is the solution to the problem", meaning that design is an "ensemble" of form and context (1964, pp.15-16). Appropriate design happens when the relationship between form and context is 'right' and the fit good. In contrast to such "goodness of fit", misfit happens when there is incongruity in a design, resulting in something being noticeable for its abnormality. A sense of what goodness of fit means is shown in the two photographs in Figure 9.
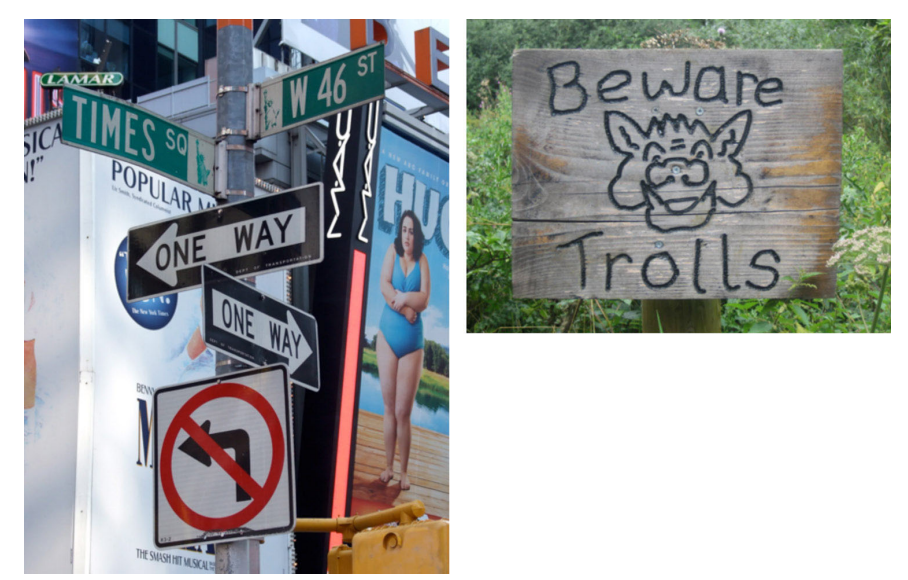

Figure 9 Two examples of graphic representation in urban and rural context (Harland, 2010).

The two photographs feature contrasting signs that directly influence human behaviour. Both imply danger but only the top photograph is realistically a matter of life or death. The 'Beware Trolls' sign is scary to a child but is more humorous to an adult. The other photograph is taken in New York's Times Square Theatre District and features statutory road signs set against a backdrop of billboards and shop fasciae. The "Beware Trolls" sign is situated in a rural country park in the middle of England. Each fits with the requirements of its context. Neither can be said to be more or less affective than the other as the contexts 
are incomparable and audience reaction has not been analysed. In a neutral setting, and with adults as the beholder, the road signs need greater legibility due to the contrast between the figure and ground being greater compared to the "Beware Trolls" sign. However, in a similar setting a child will appreciate more the Troll warning. The fixing, wood texture, and black painted incision lettering and facial depiction would not be appropriate in New York, unless used to evoke a non-urban authenticity. Inscribed wood in this style is not an appropriate medium for statutory signage. It would be a misfit.

Whereas the properties and characteristics associated with graphicality may contribute to visual expression, the determining factors that guide decisions about how graphicality happens belongs to the context in which graphicality functions. This is similar to linguistics, where the speaker and the receiver's ideolects, "the totality of speech habits of a single person at a given time" must involve shared features to achieve a mutual understanding, as shown in Figure 10, the graphic and the viewer should share a similar "common core" of understanding to achieve graphicality (Hocket, 1958, pp.331-332). When graphic forms relate to environments, such as signage systems do, the form and it's context must also share common features. As noted by Jacques Bertin, "in a signifying space any visual variable appears as meaningful" (Bertin, [1967] 1983, p.46). Graphic elements without clear meaning - outside the shared common core - become confusing as the brain searches for meaning.

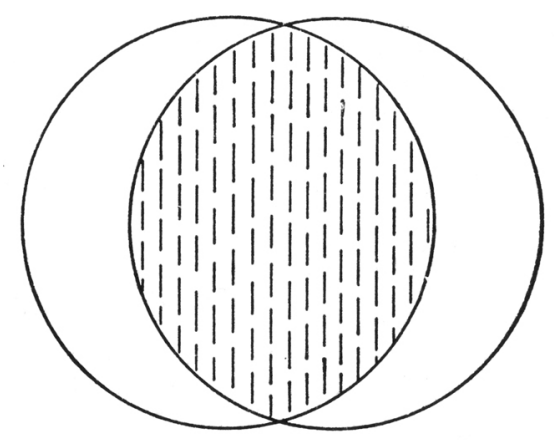

Figure 10 Two idiolects with common core (Hocket, 1958, p.322.). As two idiolects must share a common core to converse, graphic and viewer, form and context, may also relate through a common core.

\section{Conclusion}

This paper has explored the emergence, origin, and aspects of graphicality, culminating in a discussion about the role of context. This is timely in that our age increasingly exposes a proliferation of graphical form that has led us to use the notion of graphic as a defining and designated state. We live in a graphic age as much as any other, and graphic imagery is evolving in parallel to the emergence of other phenomena such as sport. Graphicality has been shown to have meaning and currency in computational mathematics, cognitive science, textuality studies, but seemingly it originated as an unacknowledged concept in literary criticism. From the intentions of Poe, we learn its most powerful association is in the 
subjective way it depicts reality, originality and the unfamiliar, whereas in computational mathematics its form - for example, nodes and links - conveys knowledge and understanding through the efficient deployment of graphs. Yet its scope is wider in cognitive science where it extends to a much wider set of graphic representations spanning what Elkins (1999, p.6) calls "non-art" as well as "art" images. In textual poetry graphicality exhibits an adventurous degree of visual emphasis in figure ground spatial relations.

Graphicality is achieved when effective visual expressions become processed in the mind, and also when visual manifestations are induced through linguistic or textual inputs. Graphical inputs can spark graphical and non-graphical thinking, and language and text can create mental imagery. This duality seems critical to the role of graphic design in meaning construction. What forms of textual and visual inputs will achieve the desired results? As it is the designer's role to construct visual meaning within their designs (Kress \& van Leeuwen, 2006), they can leverage the concepts of graphicality to communicate ideas, pre-formed for clear thinking to greater affect. This raises further questions about how we may think in preformed graphic images that precede their manifestation on screen or other surfaces such as paper. How do we design at this cognitive level where we synthesize ideas, concepts, thoughts and feelings?

The associations induced by the mathematicians use of graph theory depends on the meaning associated with otherwise abstract objects such as line. As cultural phenomena this is no different from the abstract arrangement of three lines that identify Adidas as a leading sport brand. Both are part of a set of visual elements that depend on associative, selective and ordered principles. Each has a learned set of values that impart knowledge and understanding in their signifying spaces and either display of graphicality enhances communication in their chosen context.

Future research in this field should seek to further acknowledge graphicality as an inherent human quality with different competency levels in the same way literacy and numeracy are tested. This is nothing new as there has been sporadic interest in the development of graphicacy (an often overlooked term in the literature) since the latter part of the twentieth century. Nevertheless, the importance of graphicality to graphic design is that it's aspiration to encourage originality and innovation associated with novelty, in ways that promote knowledge and understanding, provides the basis to further exploit the concept in art and design education as well as science, technology, engineering and mathematics, not to mention other disciplines such as geography. Finally, this paper promotes graphicality to be as much understood as musicality.

\section{References}

Alexander, C. (1964) Notes on the synthesis of form (Paperback edition ed.). Cambridge, Massachsettes, and London, England: Harvard University Press.

Arnheim, R. (1974) Art and Visual Perception: A Psychology of the Creative Eye. Berkeley and Los Angeles: University of California Press. 
Bertin, J. ([1967] 1983) Semiology of Graphics (W. J. Berg, Trans.). Madison: University of Wisconsin Press.

Chandler, J. (2007) Semiotics: The Basics (2nd ed.). New York: Routledge.

Cohen, D., \& Anderson, S (2006) A Visual Language: Elements of Design. London: The Herbert Press.

Del Genio, C. I., Gross, T., \& Bassler, K. E. (2011) Graphicality transitions in scale-free networks. Retrieved from http://cds.cern.ch/record/1362125

Drucker, J. (2015) Brief Graphic Performances: Minute Operas. Retrieved from http://www.drunkenboat.com/db22/reviews/brief-graphic-performances, $6^{\text {th }}$ March 2016.

Eaves, M. (2002) Graphicality: multimedia fables for "textual" critics. In E. Bergmann Loizeaux \& N. Fraistat (Eds.), Reimagining textuality: textual studies in the late age of print. Madison, Wisconsin: University of Wisconsin Press.

Elkins, J. (1999) The domain of images. New York: Cornell University Press.

Fuller, S. M. (1843) Summer on the lakes, in 1843. Boston: Charles C. Little and James Brown.

Harland, R. G. (2012) Towards an integrated pedagogy of graphics in the United Kingdom. Iridescent, Icograda Journal of Design Research, 2(1). Retrieved from https://dspace.lboro.ac.uk/2134/11349, $6^{\text {th }}$ March 2016.

Hocket, C. F. (1958) A course in modern linguistics. New York: MacMillan.

Kepes, G. (1944) Language of Vision: The Wisconsin Cuneo Press.

Kirkpatrick, E. M. (1983) Chambers 20th Century Dictionary. Edinburgh: W \& R Chambers Ltd.

Kress, G., and van Leeuwen, T. (2006) Reading images: The grammar of visual design, New York: Routledge.

MacEachren, A. M. (1995) How Maps Work: Representation, Visualization, and Design. New York and London: The Guildford Press.

Manghani, S., Arthur, P., \& Simons, J. (Eds.). (2006) Images: a Reader. London: SAGE Publications Ltd.

McGrath, B. (2013) Introduction. In B. McGrath (Ed.), Urban Design Ecologies. Chichester: Wiley.

Mitchell, W. J. T. (1986) Iconology: image, text, ideology. Chicago: The University of Chicago Press.

Paivio, A. (1986) Mental representations: A dual coding approach. New York: Oxford University Press.

Poe, E. A. (1858) The works of the late Edgar Allan Poe: with a memoir by R. W. Griswold and notices of his life and genius by N. P. Willis and J. R. Lowell. (Vol. 3, The literati). New York: Redfield.

Poe, E. A. (1880) Select works of Edgar Allan Poe, poetical and prose. With new memoir by R. H. Stoddard. (Household ed.). New York: W. J. Widdleton.

Pollin, B. R. (1989) Images of Poe's works: A comprehensive descriptive catalogue of illustrations. New York: Greenwood Press.

Poyner, R. (2002) Typographica. New York: Princeton Architectural Press.

Shimojima, A. (1999) The Graphic-Linguistic Distinction: Exploring Alternatives. Artificial Intelligence Review, 13(4), 313-335. doi:10.1023/A:1006544013197

Tufte, E. R. (1997) Visual explanations. Cheshire: Graphics Press.

UIS Fact Sheet (2013) Adult and Youth Literacy. UNESCO Institute for Statistics, Retrieved from http://tinyurl.com/qjv42u9, $6^{\text {th }}$ March 2016.

van den Broek, J., Koetsenruijter, W., de Jong, J., \& Smit, L. (2012) Visual Language: Perspectives for both Makers and Users. The Hague: Eleven International Publishing.

von Engelhardt, J. (2002) The Language of Graphics: A framework for the analysis of syntax and meaning in maps, charts and diagram. (PhD), University of Amsterdam, Institutee for Logic, Language and Computation. Retrieved from http://hdl.handle.net/11245/2.21566 
Ware, C. (2013) Information visualization: Perception for design (3rd ed.). Waltham: Morgan Kaufmann.

About the Authors:

Robert Harland researches into the fundamental nature of graphic design, and how urban graphic objects contribute to the identity, structure and meaning of the city. Prior to entering academia he spent 15 years in professional practice in London.

David Craib has been a professional communication designer for over 30 years, and, since 1994, has operated Parable Communications in Ottawa, Canada. David is a part-time professor at Carleton University, probing into fundamental aspects of visual communication design perception. 